\title{
Why There is an Intense Eastward Current in the North Atlantic but not in the South Atlantic ${ }^{1}$
}

\author{
RORY O. R. Y. THOMPSON \\ Woods Hole Oceanographic Instilution, Woods Hole, Mass.
}

22 March 1971

ABSTRACT

It is suggested that baroclinic currents may be expected to be sharper where deeper water or a decreasing Coriolis parameter lies in the direction of the Coriolis force. This is the case for the Gulf Stream between Hatteras and the Grand Banks. The suggested mechanism is that, in this case, Rossby waves propagating away must carry momentum up-gradient into the mean current. In the South Atlantic, they may carry momentum down-gradient, diffusing the mean flow.

\section{Introduction}

The question considered here is not what produces currents such as the atmospheric jet stream or oceanic Gulf Stream, but why they are so sharp, even in regions beyond the influence of inertial boundary layers. Since the baroclinicity is so much sharper than the thermal forcing, we expect nonlinearity to be important. It is well known (e.g., Starr, 1958) that the jet stream derives its energy from baroclinic eddies, which derive their energy from the baroclinicity associated with the jet stream. In the following a simple qualitative description which rationalizes this behavior is offered; moreover, it also ought to hold for certain ocean currents. The discussion is meant to be suggestive rather than definitive, in view of the number and difficulty of possible complicating factors.

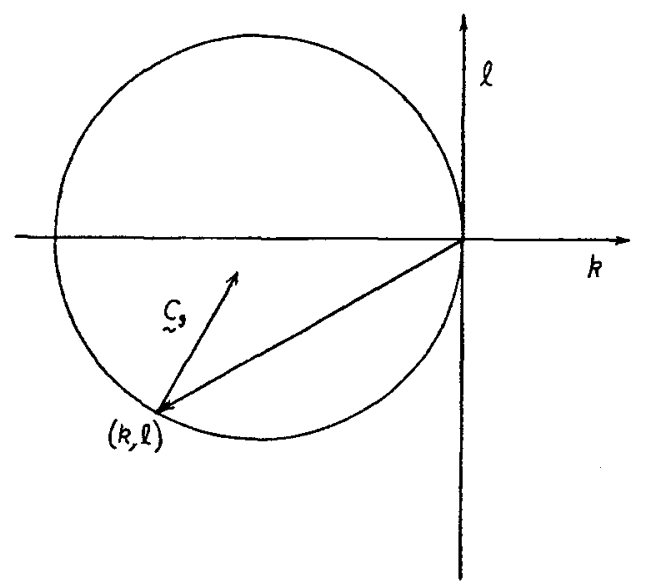

FiG. 1. The locus of the wavenumber $(k, l)$ for given $\sigma$ and for positive $\beta$.

${ }^{1}$ Contribution No. 2676 of the Woods Hole Oceanographic Institution.

\section{Mechanism}

Suppose one considers a current which is directed roughly eastward in the Northern Hemisphere, so the effective Coriolis parameter increases to the left, and suppose it develops meanders with periods long compared to a day. Then rotation will be a dominant dynamic influence. We assume that the linear theory for the waves will show the essential dynamics, though this may be doubtful for closed eddies. Further, we use barotropic dynamics for simplicity, though more complicated arguments yield the same conclusion when baroclinicity is considered. From Longuet-Higgins (1964), we have Fig. 1, relating the wavenumber vector and the direction of the group velocity for barotropic Rossby waves. We adopt a coordinate system moving with the mean local speed with $x$ and $y$, respectively, as the distances downstream (east or northeast in the diagram) and to the left, $k$ and $l$ as the associated wavenumbers, and $\sigma$ as the angular frequency. We use a $\beta$ plane approximation, with

$$
\beta=h \frac{\partial}{\partial y}\left(\frac{f}{h}\right)
$$

where $h$ is the depth. For this situation Longuet-Higgins (1964) gives the dispersion relationship

$$
\sigma\left(k^{2}+l^{2}\right)+\beta k=0 .
$$

Thus, the locus of $(k, l)$ for given $\sigma$ is a circle of diameter $\beta / \sigma$ centered at $k=-\beta /(2 \sigma)$, and the group velocity points toward the center of the circle. ${ }^{2}$

In the Gulf Stream, $\beta$ will dominantly be due to the slope of the bottom; the additional effect of the north-

${ }^{2}$ Since the coordinates move, the group and phase velocities are relative to the coordinate system. 
ward change of $f$ will be mainly to displace the whole circle slightly westward from the origin.

In order for the disturbance associated with a meander to penetrate far from the stream, the group velocity must have a component away from the stream. Thus, the disturbances seen to the north of the stream will have wavenumbers in the lower part of the circle. But the velocity is along constant phase lines perpendicular to the wavenumber vector so the disturbance velocities will be either in the second or fourth quadrants, giving a negative correlation between $u$ and $v$. In symbols, $u=-\partial \psi / \partial y, v=\partial \psi / \partial x$, where

$$
\psi=a \sin (k x+l y-\sigma t+\theta),
$$

so that an average over $x$ or $t$ gives

$$
\overline{u v}=(-l)(k)\left(a^{2} / 2\right)=-k l a^{2} / 2,
$$

where both $k$ and $l$ are negative; thus, $\overline{w v}<0$.

Similarly, south of the stream, a southward group velocity requires the wavenumber vector to be in the upper half of the circle, so there $\overline{u v}>0$; thus, meanders in the stream are associated with a convergence of momentum from both sides into the stream. For the stream as a whole,

$$
\iint \bar{u}_{y}(\overline{u v}) h d x d y>0,
$$

so that the up-gradient momentum flow must increase the kinetic energy of the mean flow; hence, the energy source of the meanders must be the potential energy. Thus, while the group velocity is directed away from the stream, the meanders lose energy to the mean flow. The up-gradient momentum flow also sharpens the jet; the jet is geostrophic, so if baroclinic, the density gradient must also sharpen, though releasing energy. Thus, the correlation of $u$ and $v$ in a propagating wave has implications with respect to the dynamics. Some of these are contrary to some institutions.

Webster (1965) found that the action of eddies in the Florida Current produces a surface flux of momentum toward higher mean speeds. While his observations were much farther south than the area considered here, the mechanism may be similar to that discussed above.

The above case may be contrasted with that in which the depth increases poleward strongly enough to overcome the change of $f$. Then $\beta<0$, and the locus of wavenumbers for given $\sigma$ is given in Fig. 2. North of the stream, where the wavenumber must be in the lower half of the circle, $u$ and $v$ must be positively correlated; i.e., $\overline{u v}>0$, so the momentum flux by the disturbances is northward. Similarly, on the south side, it is southward, so the momentum flux is away from the stream on both sides. Thus, eddies on an eastward stream over a bottom deepening poleward will tend to spread its momentum, take away energy, and make the isotherms diffuse.

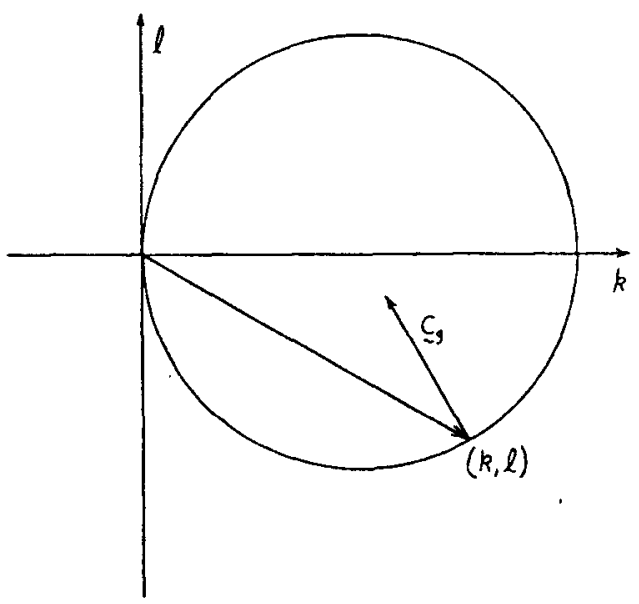

FIc. 2. The locus of the wavenumber $(k, l)$ for given $\sigma$ and for negative $\beta$.

Eliassen and Palm (1960) already gave an equation which says the northward flux of wave energy by stationary geostrophic waves is given by $-\bar{u} \overline{u v}$. This implies that (for $\bar{u}>0$ ) $\overline{u v}<0$ for standing waves if the northward flux of wave energy is positive.

\section{Applications}

Using a numerical two-layer model, Mak (1969) found that disturbances in mid-latitudes will force a poleward flux of momentum in the tropics, in agreement with the discussion here. One may expect a similar effect in the arctic regions, with equatorial momentum flux.

In the ocean, there are warm water gyres, the poleward sides of which may be expected to lie roughly between $30^{\circ}$ to $45^{\circ}$, wherein the radiational net heating changes to net cooling and wherein the wind stress curl changes sign. The above nonlinear mechanism suggests that we should expect sharp east-west currents where the large-scale bottom topography is favorable, and diffuse currents otherwise.

In the North Atlantic between 30 and $45 \mathrm{~N}$, the continental rise of the North American continent runs as a reasonable wedge shallowing to the North from about $75 \mathrm{~W}$ to about $50 \mathrm{~W}$, after which it turns north. Thus, for the suggested mechanism one may expect the Gulf Stream to be fairly sharp from Hatteras to the Grand Banks, after which it must turn north or become diffuse.

In the North Pacific, Japan has a reasonable continental rise only to $140 \mathrm{E}$, east of which there is little north-south slope. Thus, the Kuroshio may be expected to become rather suddenly diffuse east of $140 \mathrm{E}$.

In the South Atlantic, the Argentine Basin deepens all the way from 30 to $50 \mathrm{~S}$, in strong contrast to the North Atlantic. The discussion above for the case with poleward deepening suggests that one should expect the seaward extension of the Brazil Current to be diffuse 
compared with that of the Florida Current. If there is to be a strong eastward current across the South Atlantic, it apparently would have to be on the northem flank of the Rio Grande Rise at 30S, which may be too tropical or too deep, or on the Falkland Rise at 50S.

In the South Pacific, there is no north-south slope east of Australia, so one may not expect a strong eastward current there. However, there is the Chatham Rise from 40-42S extending east from New Zealand to about $170 \mathrm{~W}$. Nonetheless, there is no strong current indicated on the charts there. Perhaps New Zealand is sufficiently in the middle of the ocean not to be in a gyre. In any case, this appears to be the only place in the mid. latitudes of the Southern Hemisphere with topography capable of carrying an intense eastward current.

In the Indian Ocean, there does not appear to be an appropriate slope for an intense current eastward from Madagascar or South Africa, except for a short segment on the north of the Agulhas Bank, but the continental rise is appropriate for the intense westward Agulhas Current.

The antarctic circumpolar current seems to run mostly over basins; thus, one would not expect it to be sharpened by the topography.

\section{Summary}

The simple suggestion that planetary topography $(h / f)$ may control the sharpness of east-west currents seems to check out reasonably well. The control may be through the simple character of Rossby waves, namely, that the upslope component of group and phase velocities have opposite signs.

Acknowledgments. I thank William Schmitz and N. A. Phillips for useful comments. The research was supported by the Office of Naval Research under Contract NOOO 14-C0241.

\section{REFERENCES}

Eliassen, Arnt, and Enok Palm, 1960: On the transfer of energy in stationary mountain waves. Geofys. Publikasjoner, 22 No. 3, 1-23.

Longuet-Higgins, Michael S., 1964: On group velocity and energy flux in planetary wave motions. Deep-Sea Res., $11,35-42$.

Mak, Man-Zin, 1969: Laterally driven stochastic motions in the tropics. J. Almos. Sci., 26, 41-64.

Starr, Victor P., 1958: What constitutes our new outlook on the general circulation? J. Meteor. Soc. Japan, 36, 167-175.

Webster Ferris, 1965: Measurements of eddy fluxes of momentum in the surface layer of the Gulf Stream. Tellus, 18, 239-245. 